\title{
Modeling of the Solar Potential of Lomé, Atakpamé and Mango from Weather Data in TOGO
}

\author{
Komi Apélété Amou, Koffi Sagna*, Yendoubé Lare, Kossi Napo \\ Solar Energy Laboratory, Department of Physics, Faculty of Sciences, University of Lomé, Lomé, Togo
}

Email address:

ksagna@univ-lome.tg (K. Sagna)

${ }^{*}$ Corresponding author

\section{To cite this article:}

Komi Apélété Amou, Koffi Sagna, Yendoubé Lare, Kossi Napo. Modeling of the Solar Potential of Lomé, Atakpamé and Mango from Weather Data in TOGO. Science Journal of Energy Engineering. Vol. 5, No. 3, 2017, pp. 58-62. doi: 10.11648/j.sjee.20170503.11

Received: June 30, 2017; Accepted: July 13, 2017; Published: October 19, 2017

\begin{abstract}
In this paper, we investigate the solar potential of three different cities in TOGO (Lomé, Atakpamé and Mango) in order to determine the empirical relationships allowing us to calculate the monthly global sunshine from the relative humidity $R H$, the mean temperature $T$, and monthly average values of the non-atmospheric sunlight $H_{0}$ according to appropriate models. The models that have been chosen are those for which the availability of data necessary for their validation poses no difficulty. On the basis of the Mean Absolute Errors (MAE), the Mean Bias Error (MBE) and the Root Mean Square Error (RMSE) we were able to identify for each city the appropriate model. The advantage of this work is to present, through the determination of the MAE, MBE and RMSE parameters, the importance of the appropriate model in order to determine the photovoltaic potential estimation of a city.
\end{abstract}

Keywords: Solar Potential, Models, Mean Absolute Error, Mean Bias Error, Root Mean Square Error

\section{Introduction}

The identification of the fundamental role of sunlight in natural cycles for life such as water, carbon, oxygen and nitrogen, makes its study essential [1]. The heat of the sun causes the evaporation of the water, its condensation and the fall of the rain. In a process called photosynthesis, plants absorb carbon dioxide to produce, using solar energy, carbohydrates and oxygen. The production of organic molecules such as proteins depends on sunlight which converts nitrogen into compounds that can be absorbed by the plants we consume [2]. Today, the fields of application and use of the energy radiated by the sun are multiple. Whether in meteorology for weather forecasting [3], in medicine for its effects on health and on skin [4-6], in agriculture for certain crops and the breeding of certain animal species under conditions of sunshine and temperature, and also in the construction of buildings and their thermal comfort [7] or in the exploitation of solar energy in its various forms $[8,9]$, sunshine remains a fundamental and inescapable factor of so that one is bound to ask oneself: can one make full use of the sunshine without knowing its value? In order to estimate the value of the sunshine at any time, several correlations using climatic weather parameters have been developed. The first model developed is the linear regression of Angstrom [10]. He used the sunshine duration and the clarity index to estimate the overall sunshine. Hence modified the Angstrom model by adding other meteorological parameters such as temperature and relative humidity. This model was tested in Bahrain to obtain global sunlight [11], with a regression coefficient $R^{2}=0.83$. Several attempts to improve these empirical models have been made by substituting other parameters such as vapor pressure [12] with more or less acceptable results. Other models including more parameters and other functions such as exponential function or power have been developed by other authors [13-14, 12], as in the case of Nadir et al [11], who developed models Empirical results with excellent results. Studies on the performance of these different models show that only a few give acceptable results with very low deviations between simulated and measured values [15]. The method consists in establishing a regression by determining the parameters a, b, c, d, etc. of equations (1) to (5) for a locality where solar data are available. These unknown values a, b, c, d, etc, thus determined can be used for localities where only climatological and geographic data are available to calculate the sunshine in these places. 
In this article, we present the empirical relationships allowing us to calculate the monthly global sunshine from the relative humidity $\mathrm{RH}$, the mean temperature $\mathrm{T}$, and the mean monthly values of the sunshine out of atmosphere $H_{0}$. These models were chosen because of the availability of data needed to validate the models.

\section{Materials and Methods}

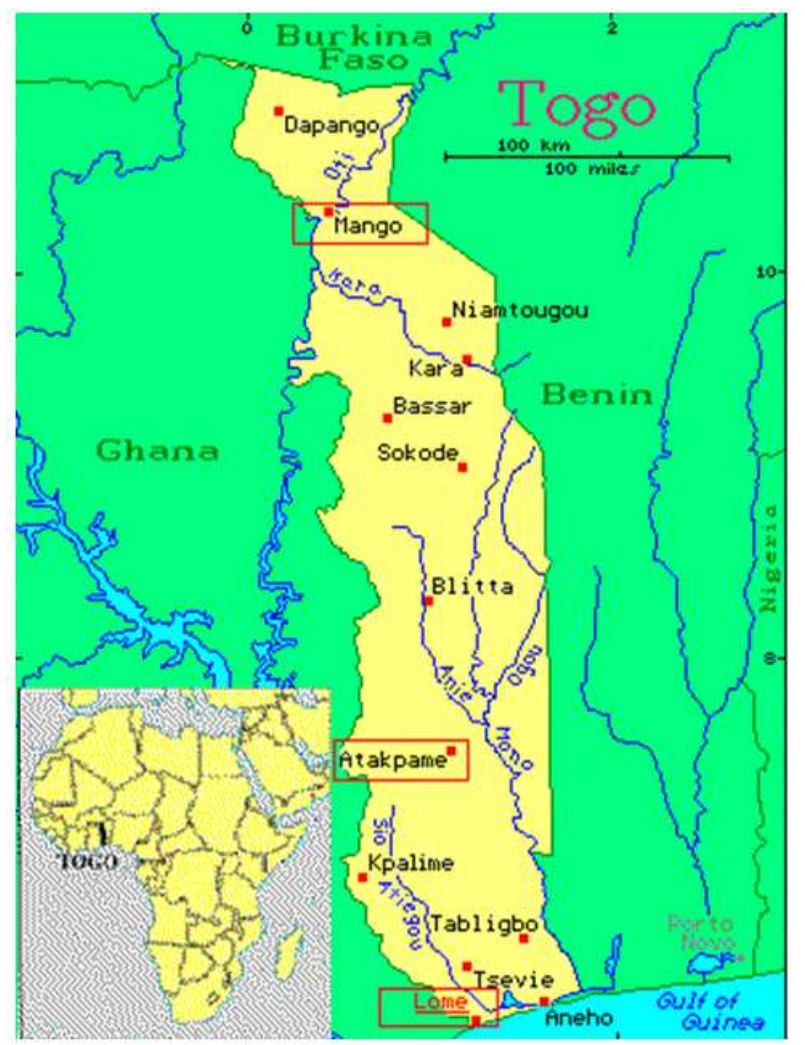

Figure 1. Map of Togo showing the three cities where the stations were installed.

Measuring apparatus were installed on the terrace of the Solar Energy Laboratory of the University of Lomé and meteorological station of Lomé (lat. $06^{\circ} 10^{\prime}$ North and long. $01^{\circ} 15^{\prime}$ East), on the terrasse of meteorological stations of Atakpamé (lat. $07^{\circ} 35^{\prime}$ North and long. $01^{\circ} 07^{\prime}$ East) and Mango (lat. $10^{\circ} 22^{\prime}$ North and long. $00^{\circ} 28^{\prime}$ East). All sensors were installed on the roof-top in a position relatively free from any external obstruction, and readily accessible for inspection and general cleaning. Measurements of global radiation were carried out using good precision pyranometer that responds to radiation within a $2 \pi$ steradian (hemispherical) field of view, which is sensitive in the wavelength range from $0.4 \mu \mathrm{m}$ to $1.1 \mu \mathrm{m}$.

The stations are scheduled to measure the global solar irradiation (GSI) from 5:00 a.m. to 8:00 p.m. daily. The GSI is measured every 30 seconds and after one hour, the meter averages and records the hourly values. The air temperature, relative humidity and GSI values respectively are measured every hour. The measurements were done from 2002 to 2009.

Different locations, with different features where took. In table 1, these sites, with some of their characteristics are shown. Seven different cities have been chosen. The choice between those seven locations was done due to the different position they have. The seven places are cities of Togo with different climates. Also, these seven locations have different altitudes upon sea level and their latitudes vary almost 5, from $6,17^{\circ}$ to $10,88^{\circ}$ North. The hourly air temperature and relative humidity data of these seven locations were recorded by the National Meteorological Institute of Togo. The three cities concerned in this paper are marked on Togo's map in red rectangle, see figure 1.

Table 1. Localities in the study.

\begin{tabular}{lll}
\hline Cities & Longitude $\left(^{\circ}\right)$ & Latitude $\left(^{\circ}\right)$ \\
\hline Lomé & 1,25 & 6,17 \\
Atakpamé & 1,12 & 7,58 \\
Mango & 0,47 & 10,37 \\
\hline
\end{tabular}

\section{Methodology}

\subsection{Presentation of the Models}

Several models of linear and exponential type are used to model the global sunlight for the three stations of Togo. These models are described by the relationships that are presented in Table 2 .

Table 2. Models using meteorological parameters.

\begin{tabular}{ll}
\hline Models & Setting parameters \\
\hline$H=a+b R H(1)$ & $R H$ : Relative Humidity \\
$H=a+b\left(R H-c H_{0}\right)(2)$ & $T$ : Mean Temperature \\
$H=a+b\left(R H-T-H_{0}\right)(3)$ & $H_{0}$ : Monthly average of sunshine \\
$H=a+b(c R H-d T)(4)$ & outside atmospheres \\
$H=a \exp (b T)+c(5)$ & $a, b, c, d$ are empirical constants to be \\
& determined for each station \\
\hline
\end{tabular}

The relative humidity and mean temperature values were obtained from the National Meteorological Institute of Togo for the three cities and the $H_{0}$ values are calculated for the whole year in order to deduct the average monthly values.

\subsection{Validation of Models}

To validate these models, the parameters presented in the equations (6) to (I.9), the deviation $(\Delta E)$, the Mean of the Absolute Values of the Errors $(M A E)$, the Mean Bias Error $(M B E)$ and the Root Mean Square Error (RMSE) are calculated.

$$
\begin{gathered}
\Delta E(\text { deviation })=\frac{\left|H_{i, m}-H_{i, c}\right|}{H_{i, m}} * 100 \\
M A E=\sum_{i=1}^{n}\left[\frac{\left(H_{i, m}-H_{i, c}\right) / H_{i, m}}{n}\right] * 100 \\
M B E=\sum_{i=1}^{n} \frac{\left(H_{i, c}-H_{i, m}\right)}{n} \\
R M S E=\left[\frac{\sum_{i=1}^{n}\left(H_{i, c}-H_{i, m}\right)^{2}}{n}\right]^{1 / 2}
\end{gathered}
$$


where $H_{i, m}$ is the th-value of the measured monthly sunshine, $H_{i, c}$ the th-value of the calculated monthly sunshine, $n$ is the total number of data and $R^{2}$ is the regression coefficient. Error e is calculated for each month individually. Relative error less than $10 \%$ is considered acceptable [14]. The MBE provides long-term information on the performance of the model. It must be low. If it is negative, then the average of the estimated values is lower than the average of the measured values.

\section{Results and Discussions}

The results of these models are summarized in Table 3.

Table 3. Summary table of different parameters of the different models.

\begin{tabular}{|c|c|c|c|c|c|c|c|}
\hline Lomé & $\mathbf{a}$ & $\mathbf{b}$ & c & d & MBE & MPE & RMSE \\
\hline I. 1 & 22,8385 & $-0,07886$ & & & 0,7218 & 5,5674 & 1,5937 \\
\hline I. 2 & 17,5664 & $-0,2257$ & -2 & & $-0,0768$ & $-0,0356$ & 0,8153 \\
\hline I. 3 & 18,0469 & $-0,2063$ & & & $-0,0494$ & 0,1641 & 0,8494 \\
\hline I. 4 & 18,7077 & $-0,1442$ & 0,9 & $-1,8$ & $-0,2316$ & $-0,8292$ & 1,1015 \\
\hline I. 5 & 5,3456 & 0,0363 & 1 & & $-0,0932$ & 0,0635 & 1,0853 \\
\hline \multicolumn{8}{|c|}{ Atakpamé } \\
\hline I. 1 & 22,8385 & $-0,07886$ & & & $-0,0635$ & $-0,9845$ & 2,07 \\
\hline I. 3 & 18,5358 & $-0,0576$ & & & 0,7474 & $-5,7335$ & 2,0922 \\
\hline I. 4 & 18,5432 & $-0,1032$ & -2 & & $-0,502$ & 1,7789 & 2,2083 \\
\hline I. 5 & 5,3456 & 0,0433 & 0 & & 0,0871 & $-0,4763$ & 1,597 \\
\hline \multicolumn{8}{|l|}{ Mango } \\
\hline I. 1 & 22,8385 & $-0,05886$ & & & $-0,3344$ & $-1,1202$ & 1,4961 \\
\hline I. 2 & 18,7654 & $-0,0957$ & -2 & & 0,2225 & 1,5191 & 1,3245 \\
\hline I. 3 & 18,9469 & $-0,0863$ & & & $-0,2338$ & $-0,8618$ & 1,3116 \\
\hline
\end{tabular}

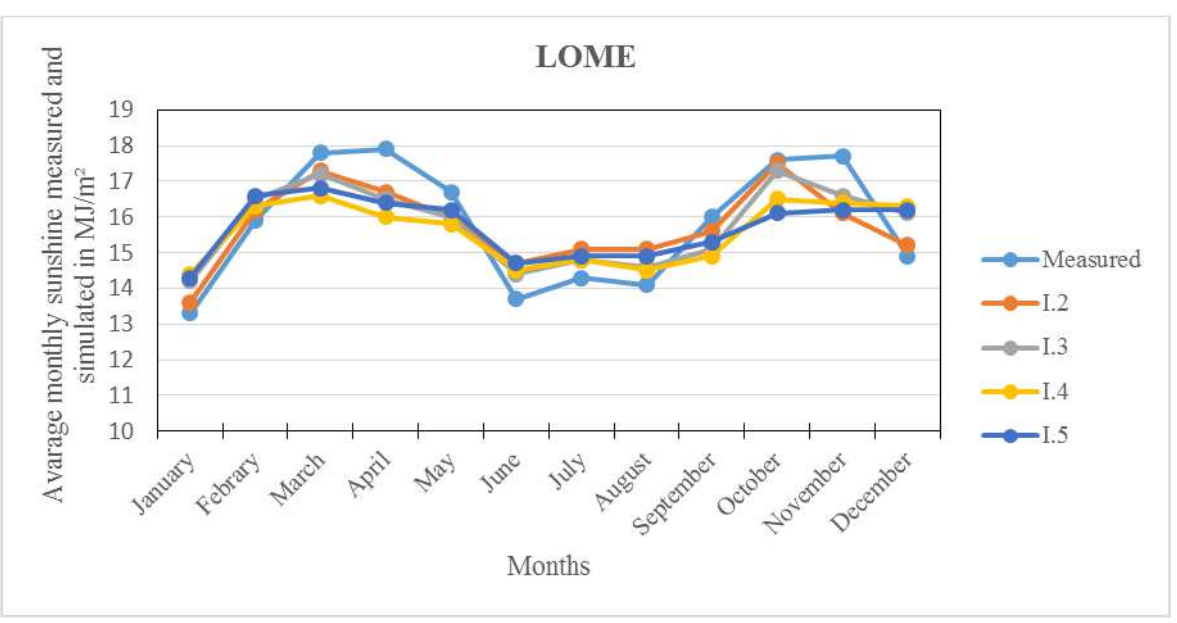

Figure 2. Monthly variations in measured and estimated sunlight from meteorological data at Lomé.

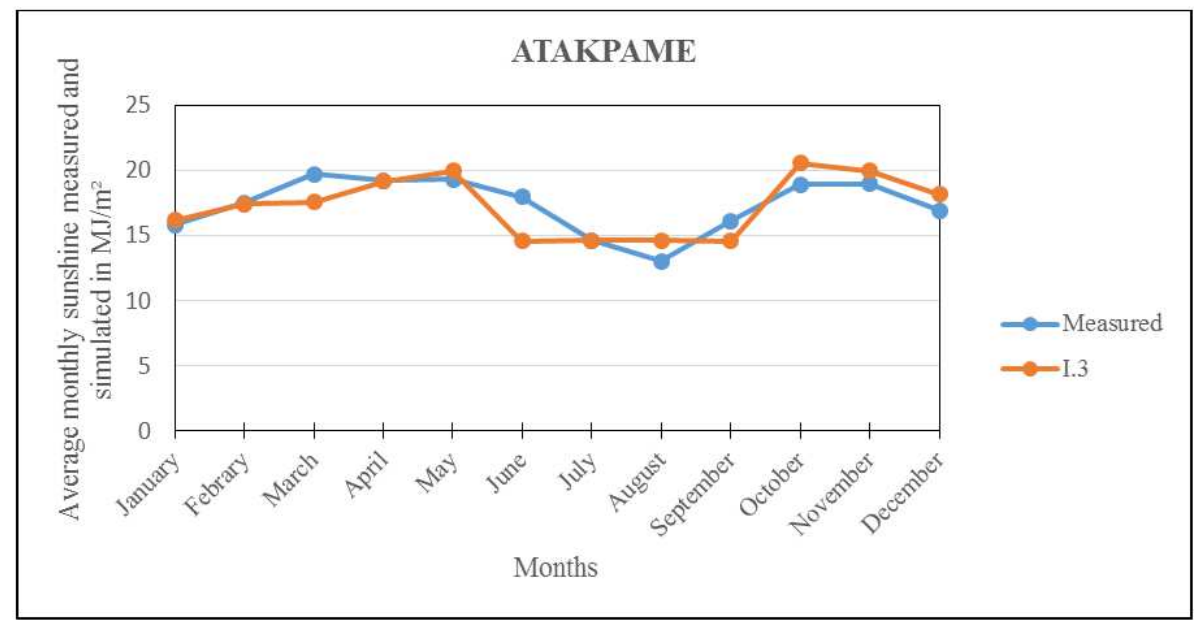

Figure 3. Monthly variations in measured and estimated sunshine from meteorological data at Atakpamé. 


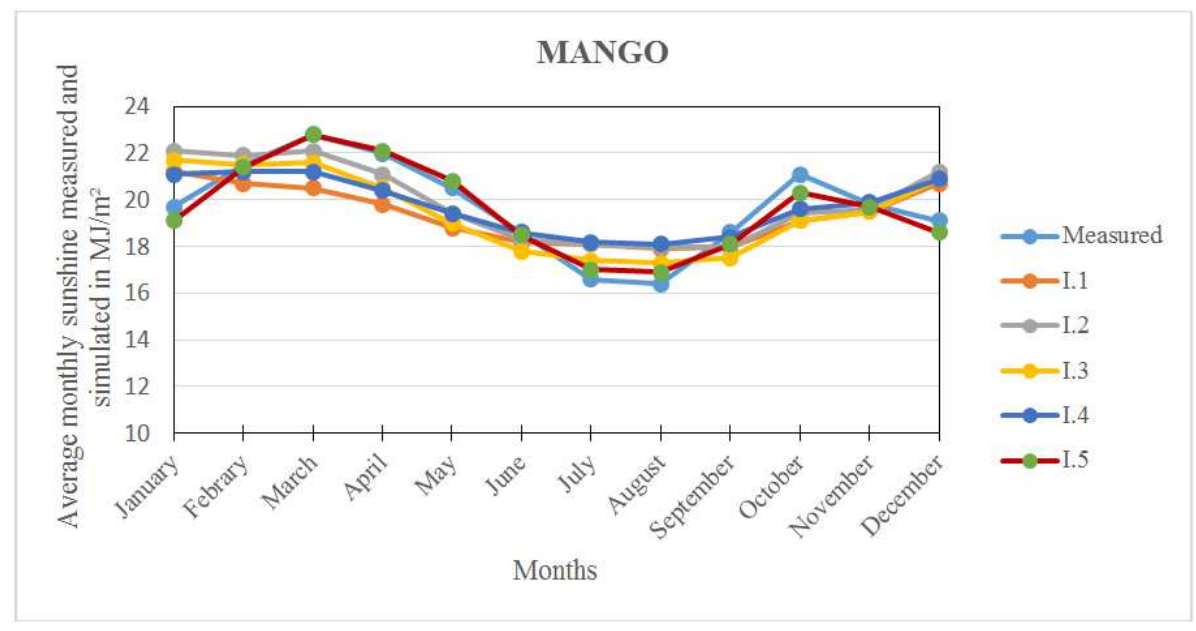

Figure 4. Monthly variations in measured and estimated sunshine from meteorological data at Mango.

Note that Figures 2, 3 and 4 show the monthly variations of the measured and estimated sunlight from the meteorological data respectively in Lomé, in Atakpamé and in Mango. These figures clearly show that there is a good correlation between the characteristics of the measured values and those predicted by the estimates given by the models, especially since the difference between the measured and estimated values is between $3 \%$ and $11 \%$. Moreover, in figure 3 , only the characteristics of a single model for comparison with the measured data of Atakpamé's station are considered. However, for Lomé (figure 2) and Mango (figure 4), the percentage deviations from the measured values are less than $10 \%$. For Mango, the maximum deviation on the monthly values is $10.2 \%, 12.6 \%, 10.5,10.7 \%$ and $3.39 \%$ respectively for models corresponding to equations (1) to (5). For Lomé (figure 2), these values are 9.1\%, 7.1\%, 10.5\% and $8.6 \%$ respectively for models Equations (2) to (5). The results of the model of equation (5) are better if we refer to the values of $M B E, M A E, R M S E$. For Atakpamé (figure 3), only the model corresponding to equation (3) gave an acceptable result with a maximum deviation of about $10 \%$. From these results, they can notice that the model (5) describes well the average monthly sunshine of Mango, while model (3) is appropriate to those of Atakpamé and Lomé.

\section{Conclusion}

In this paper, we have identified the appropriate model to be applied for each station and studied the monthly variations in the measured and estimated sunshine of each of the identified stations. From these different models, we were able to calculate the sunshine from meteorological data with deviations always about $10 \%$. But, since these coefficients are specific to each city, these models do not allow to determine the sunshine in other cities of Togo. Based on the value of the characteristic parameters as the Mean Absolute Error (MAE), the Mean Bias Error (MBE) and the Root Mean Square Error (RMSE), we were able to identify the model (5) is better for the city of Mango whereas it is the model (3) which is better for the city of Atakpamé and Lomé in the estimates of the solar potential.

\section{References}

[1] William C. Burger, Perfect Planet, clever species-How unique are we? P 24, 34, 2003.

[2] David Suzuki, l'équilibre sacré - Redécouvrir sa place dans la nature, trad. Jean Chapdelaine Gagnon, Boréal, p. 115, 2007.

[3] Skeiker K. Correlation of global solar irradiation with common geographical and meteorological parameters for Damascus province, Syria, Energy conversion and Management, 47, (4) 331-345, 2006.

[4] Carper Jean, Food, Your miracle medicine, Harper Perennial, New York 1994.

[5] The Natural pharmacy, Health concerns: seasonal Affective Disorder,

www.gnc.com/wellness/napharm/concern/seasonnal_Affective Disorder.html

[6] Groom KN, O'Connor ME, Relation of light and exercise to seasonal depressive symptoms: preliminary development of a scale. Percept Mot Skills; 83: 379-83, 1996.

[7] Dorota A. Chwieduk, Recommendation on modeling of solar energy incidenton a building envelope, Elsevier, Renewable Energy 34, 736-741, 2009.

[8] Petela R., Energy analysis of the solar cylindrical parabolic cooker, Solar Energy, 79, (3), 221-233, 2005.

[9] Qiu, K. and Hayden, A. C. S. Development of a silicon concentrator solar cell based TPV power system, Energy Conversion and Management, 47, (4), 365-376, 2006.

[10] Angstrom A., Solar and terrestrial radiation. Q. J. R. Meteorol. Soc. 50, 121-126, 1924.

[11] Nadir A. E. New empirical models for global solar radiation over Bahrain, Energy Conversion and Management Vol. 39 No 8 pp. 827-835, 1998 .

[12] Ododo JC. Sulaiman AT. Aidan J. Yguda MM. Ogbu FA. The importance of maximum air temperature in the parameterization of solar radiation in Nigeria. Renewable Energy; 6: 775-63, 1995. 
[13] Glower J. McGulloch JSG. The empirical relation between solar radiation and hours of sunshine. Quart J R Met Soc 1958: 84: 172.

[14] Ojosu JO. Komolafe LK. Modeels for estimating solar radiation abailability in South Western Nigeria. Nig J Solar Energy; 6: 69-77, 1987.
[15] C. Ertekin, O. Yaldiz, Comparison of some existing models for estimating global solar radiation for Antalya (Turkey) Energy Conversion and Management 41, 311-330, Pergamon, 2000 . 